\title{
RESSIGNIFICANDO O ENSINO DE GEOGRAFIA ATRAVÉS DE PRÁTICAS DE SOLO
}

\author{
Anderson Felipe Leite dos SANTOS ${ }^{1}$ \\ Lediam Rodrigues Lopes Ramos REINALDO²
}

\section{Resumo}

O solo é um recurso natural muito importante para a vida na terra, possuindo um importante papel ecológico, sendo o principal substrato para 0 desenvolvimento das plantas, vivendo nele diversos animais. Experimentos sobre a erosão do solo se mostram como importantes recursos didáticospedagógicos para se trabalhar as consequências causadas pela ação natural e principalmente antrópica sobre o solo, nas abordagens da disciplina de Geografia que estuda as diversas relações entre o homem e o meio. Diante desse entendimento, o objetivo aqui proposto consiste em analisar a importância da utilização de práticas de solos como recurso metodológico em prol do desenvolvimento de uma consciência ambiental e de um melhor processo de ensino e aprendizagem por parte dos alunos. As atividades foram desenvolvidas durante o Residência pedagógica de Geografia da Universidade Estadual da Paraíba, com alunos do $8^{\circ}$ ano da Escola Municipal Judith Barbosa de Paula Rêgo, localizada no município de Queimadas, no estado da Paraíba. A partir dos resultados obtidos comprovou-se que a utilização de recursos metodológicos em sala de aula melhora o aprendizado dos alunos, que mostram em sua maioria um maior interesse pelo assunto trabalhado.

Palavras-chave: Educação básica; Erosão; Ensino de solos; Residência pedagógica; Práticas didáticos-pedagógicos.

\section{RE-MEANING GEOGRAPHY TEACHING THROUGH SOIL PRACTICES}

\begin{abstract}
Soil is a very important natural resource for life on earth, having an important ecological role, being the main substrate for the development of plants, living in it several animals. The development of experiments on soil erosion are shown as important didactic-pedagogical resources to work the consequences caused by the natural and mainly anthropic action on the soil, in the approaches of the discipline of Geography that studies the various relationships between man and the environment. In view of this understanding, the objective proposed here is to analyze the importance of using soil practices as a methodological resource

\footnotetext{
1 Graduando do Curso de Geografia da Universidade Estadual da Paraíba - UEPB; Rua Baraúnas, 351, Bairro Universitário. Cep 58429-500; Campina Grande/PB. E-mail: andersonfelipeleitedossantos@gmail.com

2 Doutora em Recursos Naturais pela Universidade Federal de Campina Grande - UFCG. Professora Titular do Departamento de Geografia da Universidade Estadual da Paraíba - UEPB. Rua Baraúnas, 351, Bairro Universitário. Cep 58429-500; Campina Grande/ PB. E-mail: lediamrodrigues@gmail.com
} 
for the development of an environmental awareness and a better teaching and learning process by students. The activities were developed during the Pedagogical Residence of Geography of the State University of Paraíba, with students of the 8th year of the Municipal School Judith Barbosa de Paula Rêgo, located in the municipality of Queimadas, in the state of Paraíba.

Keywords: Basic education; Erosion; Soil teaching; Pedagogical residency; Didactic-pedagogical practices.

\section{ENSEÑANZA DE GEOGRAFÍA RECOMENDABLE A TRAVÉS DE PRÁCTICAS DEL SUELO}

\section{Resumen}

El suelo es un recurso natural muy importante para la vida en la tierra, tiene un papel ecológico importante, siendo el sustrato principal para el desarrollo de las plantas, viviendo en él varios animales. El desarrollo de experimentos sobre la erosión del suelo se muestra como importantes recursos didáctico-pedagógicos para trabajar las consecuencias causadas por la acción natural y principalmente antrópica en el suelo, en los enfoques de la disciplina de Geografía que estudia las diversas relaciones entre el hombre y el medio ambiente. En vista de esta comprensión, el objetivo aquí propuesto es analizar la importancia de utilizar las prácticas del suelo como recurso metodológico para el desarrollo de una conciencia ambiental y un mejor proceso de enseñanza y aprendizaje por parte de los estudiantes. Las actividades se desarrollaron durante la Residencia Pedagógica de Geografía de la Universidad Estatal de Paraíba, con alumnos del octavo año de la Escuela Municipal Judith Barbosa de Paula Rêgo, ubicada en el municipio de Queimadas, en el estado de Paraíba.

Palabras clave: Educación básica; Erosión; Enseñanza del suelo; Residencia pedagógica; Prácticas didáctico-pedagógicas.

\section{INTRODUÇÃO}

O solo é um recurso natural muito importante para a vida na terra, possuindo um importante papel ecológico, sendo o principal substrato para o desenvolvimento das plantas, vivendo nele diversos animais. É composto basicamente de água, ar, minerais (argila, areia e silte) e material orgânico morto e vivo. Sendo assim, é no solo que caminhamos, construímos nossas casas e as estradas, e plantamos tudo aquilo necessário para sobreviver. Porém, com a degradação dos solos, causada pela a ação antrópica, através das práticas do desmatamento e das queimadas, que levam à diminuição de nutrientes minerais e de matéria orgânica, está-se ameaçando a biodiversidade, e restringindo e $\backslash$ ou impossibilitando o uso do solo para a agricultura. 
Embora muitas vezes negligenciado, a degradação dos solos por processos, tais como erosão, poluição, deslizamentos e assoreamentos de cursos d'água, pode ser considerado um dos mais importantes problemas ambientais e socioeconômicos atuais, que afeta tanto áreas rurais quanto áreas urbanas (BOARDMAN, 1999). A falta de sensibilidade e consciência em relação a importância do solo pode contribuir para sua degradação, seja por mau uso ou ocupação desordenada. Dessa forma, o acesso ao conhecimento sobre solos pode auxiliar em sua conservação. (LIMA, 2006; MUGGLER et al., 2006).

Nesse contexto, o ensino de solo nas escolas desde os primeiros anos do ensino fundamental, é de extrema importância, pois se faz necessário que os alunos vejam a importância de se preservar o solo e a vegetação, que o protege da erosão e que é essencial para a fauna, pelo fato que os animais dependem da vegetação para se alimentar. Araújo (2010, p.24) relata que:

"A atividade humana acelera o processo de desgaste e perda do solo, entre os fatores causadores da erosão estão práticas agrícolas sem o manejo adequado do solo, as culturas e cultivos não adaptados às características dos solos, as queimadas e o desmatamento. Os ricos de erosão dependem tanto das condições naturais quanto dos modelos de uso da terra”.

Dessa maneira, o professor em sala de aula pode demonstrar a importância de se preservar o solo, através dos experimentos de solos, no qual toda a turma irá ver na prática que realmente se cuidarmos de forma correta do solo, todos se beneficiarão, pois como já se sabe, uma vez desgastado, aquele determinado solo nunca mais poderá ser utilizado.

No entanto, o que se observa é que muitos professores possuem dificuldade em desenvolver novas metodologias para se trabalhar em sala de aula com os alunos, em decorrência que em muitos cursos de licenciatura plena, os diversos componentes curriculares são dedicados muitas vezes somente à teoria, esquecendo-se da prática e ficando assim uma lacuna na preparação dos professores para a sala de aula.

Sendo assim, é de extrema importância que na formação inicial os licenciandos possam terem conhecimento dos contextos escolares, a partir da convivência com outros professores da educação básica, para que possam 
desenvolverem metodologias que propiciem um maior interesse e rendimento dos alunos tanto do ensino fundamental quanto do médio, podendo associar teoria e prática no cotidiano escolar.

Então a partir dos programas oferecidos pelo Ministério da Educação, como o Residência Pedagógica, a uma integração do ensino superior com a educação básica, sendo possível amenizar o distanciamento dos licenciandos com a realidade escolar, que podem além de conhecerem o âmbito escolar, desenvolverem metodologias de ensino capazes de melhorar a aprendizagem dos alunos em sala de aula. De acordo com Imbernón (2010, p.85):

“[...] a formação centrada na escola envolve estratégias empregadas pelos formadores e pelos professores para dirigir os programas de formação de modo que respondam às necessidades definidas da escola e para elevar a qualidade de ensino e da aprendizagem em sala de aula e nas escolas”.

Destaca-se assim que no exercício professoral, é necessário despertar nos alunos o interesse para aprenderem sobre os diversos conteúdos, e uma maneira para isso, é através dos experimentos desenvolvidos em sala, que fazem com que os alunos possam se tornarem sujeitos ativos do processo de aprendizagem. Ressalta-se que os alunos necessitam realizar todos os processos dos experimentos desde da montagem até a sua finalização, possibilitando o desenvolvimento do trabalho em grupo e despertando a criticidade dos alunos, pois leva-os a refletirem sobre aquele determinado problema estudado. Assim os mesmos poderão passarem informações aprendidas para outros membros da escola e da sociedade em geral, tornando a aula ainda mais divertida, proporcionando com que os alunos tenham uma visão mais ampla do assunto trabalhado. Segundo Assis, Lima e Gomes (2002, p.169):

“O professor como sujeito que não reproduz apenas o conhecimento pode fazer do seu próprio trabalho de sala de aula um espaço de práxis docente e de transformação humana. É na relação refletida e na redimensão de sua prática que o professor pode ser agente de mudanças na escola e na sociedade".

Nesse contexto, o presente trabalho será debatido a importância do Programa Residência Pedagógica (PRP), desenvolvida na Universidade Estadual 
da Paraíba - UEPB, no campus I, em prol do aperfeiçoamento das metodologias que propiciem um ensino de Geografia capaz de tornar o aluno um sujeito crítico e consciente, capaz de lidar com diversas situações problemas do seu cotidiano. Desse modo, o objetivo aqui proposto consiste em analisar a importância da utilização de práticas de solos como recurso metodológico em prol do desenvolvimento de uma consciência ambiental e de um melhor processo de ensino e aprendizagem por parte dos alunos. Assim sendo possível mostrar para os estudantes a importância da preservação da cobertura vegetal do solo para a biodiversidade e para os próprios seres humanos.

Para embasar este trabalho, foi realizada uma pesquisa bibliográfica, no qual a coleta de informações se deu através do levantamento e análise das teorias dos autores como Assis, Lima e Gomes (2002); Frasson e Werlang (2010); Moreira (1992); Ruellan (1988); Souza (2007); entre outros autores que trabalham com a temática em análise.

Com a finalidade de alcançar as ações propostas no trabalho, realizamos no primeiro momento a explanação do conteúdo sobre solo, mostrando a importância de se preservar a cobertura vegetal do solo, para evitar a erosão; no segundo momento, os alunos responderam um questionário, antes da realização de cada experimento; no terceiro momento, houve a realização dos experimentos com os alunos, no qual os estudantes desenvolveram todo o processo desde da montagem até a realização e no quarto e último momento, os alunos responderam mais um questionário sobre cada experimento para avaliar-se que mudanças houveram nas respostas apresentadas pelos alunos, em prol de analisar se as práticas contribuíram para um melhor processo de aprendizagem dos discentes.

\section{METODOLOGIA}

Para a realização deste trabalho utilizou-se de uma abordagem qualitativa em que procurou-se evidenciar todas as dimensões do fenômeno analisado. A construção do trabalho contou com a realização de pesquisas bibliográficas, em que foram consultados textos que contemplam a temática em análise; e, com uma pesquisa empírica constituída pelo desenvolvimento de 
uma proposta de intervenção realizada no contexto da experiência docente oportunizada pela participação no Programa Residência Pedagógica.

Ludke e André (1986) destacam que em estudos qualitativos é fundamental que o pesquisador invista seus esforços na tentativa de capturar as concepções dos participantes. Ou seja, que ele compreenda a maneira como os sujeitos envolvidos na investigação encaram as questões centrais do estudo.

A pesquisa empírica ocorreu em uma turma do $8^{\circ}$ ano do ensino fundamental II, da Escola Municipal Judith Barbosa de Paula Rêgo, localizada no município de Queimadas, no estado da Paraíba. O principal objetivo dos experimentos realizados foi de mostrar a importância de se preservar a cobertura vegetal do solo para a manutenção da biodiversidade e evitar a erosão. Antes e depois da realização dos experimentos foram utilizados questionários junto a turma, para obtenção de dados com relação as práticas de solo desenvolvidas.

Figura 1: Localização da Escola Municipal Judith Barbosa de Paula Rêgo, no município de Queimadas - PB

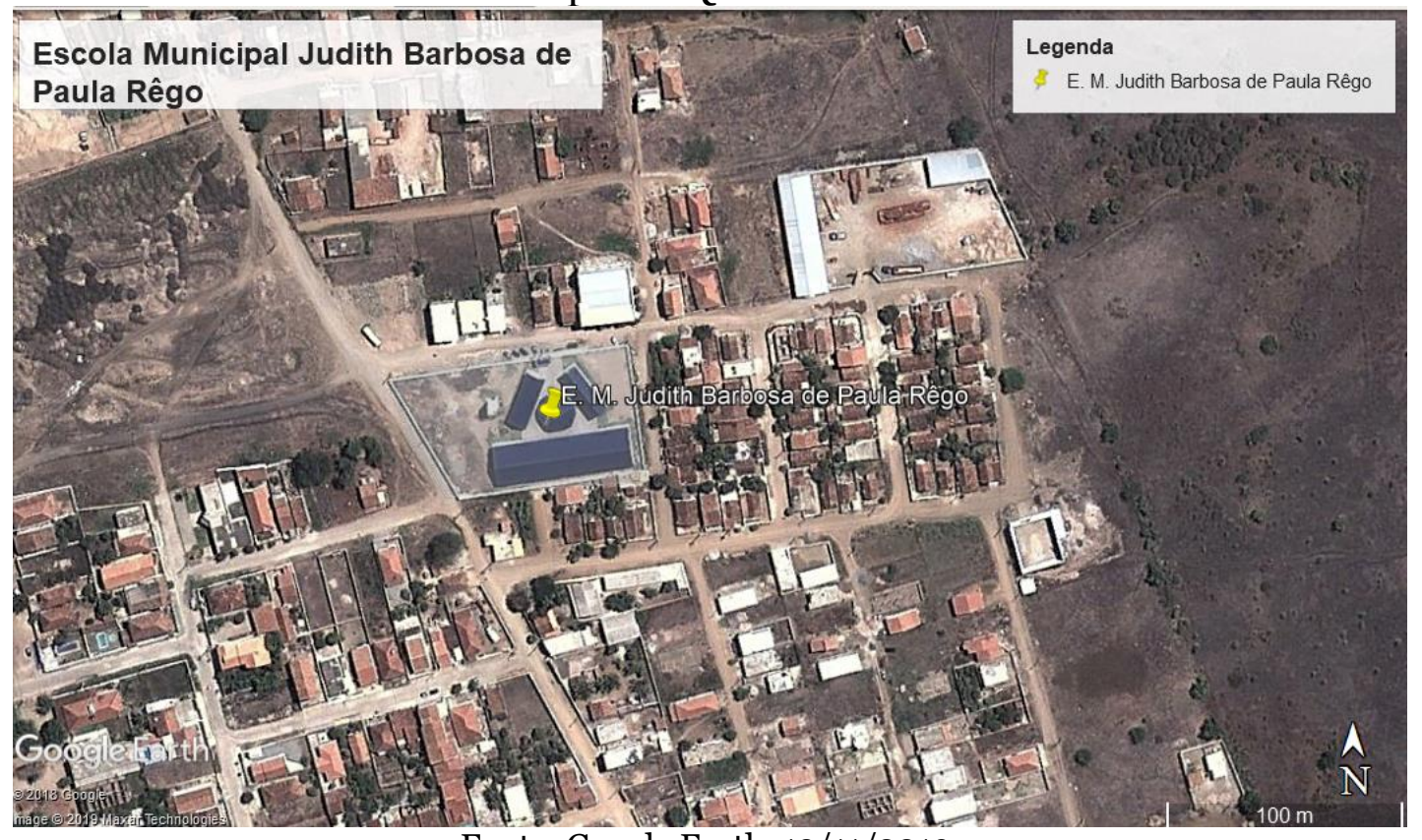

Fonte: Google Earth, 13/11/2019. 


\title{
APORTE TEÓRICO
}

\section{A importância do Programa Residência Pedagógica para os graduandos das diversas licenciaturas}

O Programa Residência Pedagógica é uma das ações que integram a Política Nacional de Formação de Professores e tem por objetivo induzir o aperfeiçoamento da formação prática nos cursos de licenciatura, promovendo a imersão do licenciado na escola de educação básica, a partir da segunda metade do curso. Dessa forma, o Residência Pedagógica, serve como uma forma de aproximar os alunos da graduação das diversas licenciaturas com a sala de aula, pois os residentes exercem a função de professores, assumindo turmas do ensino fundamental e médio das escolas públicas participantes. Vale ressaltar que cada residente tem o auxílio do professor preceptor, que os ajudam a realizar todas as atividades no âmbito escolar e do docente orientador, que estabelece a relação entre a teoria e a prática nos diversos encontros realizados na universidade com todos os envolvidos. Sendo assim O Programa de Residência Pedagógica visa:

\begin{abstract}
I. Aperfeiçoar a formação dos discentes de cursos de licenciatura, por meio do desenvolvimento de projetos que fortaleçam o campo da prática e conduzam o licenciando a exercitar de forma ativa a relação entre teoria e prática profissional docente, utilizando coleta de dados e diagnóstico sobre o ensino e a aprendizagem escolar, entre outras didáticas e metodologias; II. Induzir a reformulação do estágio supervisionado nos cursos de licenciatura, tendo por base a experiência da residência pedagógica; [...] IV. Promover a adequação dos currículos e propostas pedagógicas dos cursos de formação inicial de professores da educação básica às orientações da Base Nacional Comum Curricular (BNCC) (Edital CAPES, 06/2018) [...] A residência pedagógica consiste na imersão planejada e sistemática do aluno de licenciatura em ambiente escolar visando à vivência e experimentação de situações concretas do cotidiano escolar e da sala de aula que depois servirão de objeto de reflexão sobre a articulação entre teoria e prática. Durante e após a imersão o residente deve ser estimulado a refletir e avaliar sobre sua prática e relação com a profissionalização do docente escolar, para registro em relatório e contribuir para a avaliação de socialização de sua experiência como residente (Edital CAPES, 06/2018).
\end{abstract}

Então, a partir do momento que se inicia o trabalho dos residentes em sala de aula, é possível colocar em prática tudo aquilo que se aprendeu até o momento na graduação, além de conhecer mais de perto a área de atuação e a 
realidade de uma turma, pelo fato que os licenciandos só imaginam como é ser professor, sem conhecer como seja exercer a docência na prática, visto que só no final dos cursos de licenciatura que é oferecido os estágios, considerados como o momento mais aguardado, pois é nele que a maioria decide se gosta ou não de exercer o exercício de professor. De acordo com Althaus (1997, p.72) o despertar pedagógico começa a se manifestar apenas [...] no momento em que os alunos realizam estágios nas escolas". Com isso, o Residência Pedagógica além de promover a inserção do graduando nas salas de aulas da educação básica, ajudando na sua formação profissional, também serve para ajudar quem está indeciso quanto à questão de exercer o exercício de professor.

Portanto, a partir da vivência em sala de aula é possível desenvolver diversas metodologias, ajudando os alunos a melhorarem o seu entendimento a respeito dos conteúdos e participarem cada vez mais das aulas, sendo tarefa do professor mostrar que o aluno é capaz de discutir sobre os diversos conteúdos, como mostra Paulo Freire (1996), quando observa que tanto professores como alunos, assumindo-se sujeitos da produção do saber, convençam-se definitivamente de que ensinar não é transferir conhecimento, mas criar as possibilidades para a produção ou construção social do aluno. Logo, mesmo os professores tendo diversas posturas pedagógicas em sala de aula, sempre tem que favorecer o aspecto crítico do aluno, para gerar um espaço de aprendizagem.

A partir do que foi discutido, na próxima seção trataremos sobre os experimentos de solos como recurso didático-pedagógico na disciplina de Geografia.

\section{Os experimentos de solos como recurso didático-pedagógico na disciplina de Geografia}

O solo, apesar de ser um recurso natural indispensável para a vida dos ecossistemas terrestres, não tem seu devido reconhecimento nas abordagens da disciplina de geografia no ensino fundamental e médio, no qual muitas vezes são passados pelo professor informações superficiais sobre o solo, deixando lacunas abertas sobre o conhecimento do solo, que é um recurso tão importante 
para a vida humana e a biodiversidade. Sendo assim, sem informações necessárias sobre o solo, as pessoas o veem apenas como o lugar onde "pisam", não tendo o cuidado necessário para mantê-lo preservado, pois não tiveram uma educação em solos. De acordo com Ruellan (1988):

Na educação em solos uma das maneiras de atingir esse objetivo é promover estudos integrados entre ensino, pesquisa e extensão, integrando universidades e comunidades externas (professores e estudantes de escolas de educação básica, sociedade em geral e agricultores).

Porém, com as lacunas deixadas pelos cursos de formação de professores, e a falta de integração da universidade com a comunidade, as pessoas não estão tendo uma educação em solos, sendo assim, deixando de saber sobre a importância de sua preservação. Observa-se constantemente, por exemplo, o aumento de queimadas, por muitos agricultores, em diversas regiões do mundo, para "limpar" campos agricultáveis ou pastos, mas não sabem eles, que as queimadas destroem as camadas superficiais do solo, acelerando seu processo de desgaste e esgotamento. Dessa forma, se tivesse, os estudos integrados entre ensino, pesquisa e extensão, integrando universidades e comunidades externas, como mostra Ruellan (2008), essas práticas destruidoras do solo poderiam ser evitadas, contribuindo para a sua preservação.

De acordo com Frasson e Werlang (2010) a educação em solos está sendo trabalhada principalmente em áreas específicas de agronomia, silvicultura, entre outras e muito superficialmente em geografia, o que não levou a uma popularização do conhecimento sobre o solo nas escolas. Sendo assim, um fator decisivo para essa superficialidade do ensino de solo nas escolas é o livro didático, que traz poucas informações sobre o solo e muitas vezes os professores não aprofundam o assunto retratado. No entanto, o livro didático é um recurso que o professor tem para o auxiliar no processo de ensino e aprendizagem, não se podendo deter, apenas as informações contidas nele. Segundo Nunes, Azevedo e Silva (2016, p.274):

O livro didático se constitui em um importante instrumento no processo de ensino-aprendizagem, facilitando a apropriação de conceitos por meio da linguagem escrita e imagética. Para o ensino de Geografia, sobretudo em escolas públicas, o livro 
didático torna-se um elemento de grande relevância por permitir o trabalho com diversas informações, como mapas, imagens, gráficos, tabelas, textos e exercícios. Entretanto o livro não deve ser considerado o único recurso didático a ser utilizado, tendo em vista a necessidade de diversificar as práticas pedagógicas para dinamizar as aulas e favorecer a construção de conhecimentos pelos alunos.

Por isso a importância do professor utilizar, diversos outros recursos didático pedagógicos, além do livro didático, para se trabalhar sobre o solo em sala de aula, como por exemplo, os experimentos de solos, que enriquecem o conhecimento dos educadores e também dos educandos. Dessa forma de acordo com Souza (2007, p. 110): [...] é possível a utilização de vários materiais que auxiliem a desenvolver o processo de ensino e aprendizagem, isso faz com que facilite a relação professor - aluno - conhecimento.

Apesar disso, os professores não utilizam outros recursos didáticos, para trabalhar os conteúdos sobre solos, muitas das vezes por não saberem como trabalhar de forma "diferente" do tradicional, trazendo situações que façam com que os alunos conheçam na prática a importância do solo. Castold e Polinarski (2009, p.685) afirma que:

[...] com a utilização de recursos didático- pedagógico, pensa-se em preencher as lacunas que o ensino tradicional geralmente deixa, e com isso, além de expor o conteúdo de uma forma diferenciada, fazer dos alunos participantes do processo de aprendizagem.

Sendo assim na próxima seção iremos tratar sobre a importância da formação de professores para o ensino de solo na educação básica.

\section{A importância da formação de professores para trabalharem sobre a conservação do solo na Educação Básica}

A educação básica é o primeiro nível do ensino escolar no Brasil, compreendendo três etapas, a educação infantil, o ensino fundamental I e II e o ensino médio, no qual na educação infantil e no ensino fundamental I, vão atuar pedagogos dando todas as disciplinas, e no ensino fundamental II e ensino médio professores das diferentes áreas (História, Geografia, Biologia, Matemática), entre outros. Compreende-se dessa forma, que desde de pequenas 
as crianças já entram em contato com as diversas disciplinas, que fazem parte de toda sua vida escolar, podendo destacar a geografia, que é a ciência que estuda o espaço geográfico, no qual passa por diversas transformações, causadas principalmente pelo homem (ação antrópica), que modifica a natureza, em prol de benefícios para si próprio. Para Moreira (1992, p.88):

O espaço geográfico é a história em seu devir perpétuo, isto é, encontra-se em permanente processo de transformação, acompanhando e condicionando a evolução das sociedades: "O espaço é a sociedade pelo simples fato de que é a história dos homens produzindo e reproduzindo sua existência por intermédio do processo de trabalho".

Porém, esse processo de transformação do espaço pela ação antrópica, causa diversos problemas ambientais, como a degradação do solo, um recurso natural necessário para que haja a existência da biodiversidade e dos próprios seres humanos. O que se pode analisar, é que muitas pessoas não conhecem a importância de se conservar o solo, pois muitas vezes viram o assunto na escola, mas não houve uma demonstração, por isso a união entre a teoria e a prática em sala de aula, desde dos primeiros anos do ensino básico é de extrema importância, pois as crianças e os jovens veem os conteúdos (teoria) e aprofundam através das práticas.

Sendo assim, é necessário que os professores tenham em sua formação acadêmica, uma junção da teoria com a prática para poder em sala de aula desenvolver os diversos experimentos, facilitando o aprendizado dos seus alunos. Segundo Pimentel (2014), é necessário que os conhecimentos teóricos tenham sentido e significado para que se possa perceber a relação entre teoria e as ações cotidianas. Por isso a importância, de realizar as práticas de solos, aproximando o conteúdo do cotidiano do aluno, através das situações expostas através dos experimentos, fazendo-os refletirem sobre aquele determinado assunto.

De acordo com Lima et al. (2007) o tema solo pode e deve ser abordado durante todo o curso fundamental e médio, em todas as matérias e disciplinas, de forma interdisciplinar, com diferentes graus de complexidade de acordo com o ciclo em que se está trabalhando, para tanto fazendo uso de recursos diversos 
que favoreçam a construção do conhecimento a respeito da temática. Dessa forma, existe inúmeras formas para ensinar o tema solo tanto no meio urbano ou rural. Acreditamos que uma abordagem interdisciplinar fará com que os alunos adquiram maior interesse no estudo do solo e consigam melhor entender o papel e as funções que exerce no meio ambiente, o que, sem dúvida, permitirá a aquisição e aumento da necessária consciência ecológica (LIMA et al., 2007).

Logo, é de suma importância que se trabalhe com o solo, tanto em ciências, geografia, entre outras; destacando sua importância desde das primeiras civilizações que usavam as tintas provindas dos solos para fazerem desenhos, sendo uma forma de se comunicarem e mostrarem um pouco do seu dia a dia. De acordo com Gombrich (2008):

A história do surgimento da tinta esta atribuída aos primeiros vestígios de tintas naturais feitas pelo homem de que temos notícias, as pinturas pré-históricas feitas em cavernas pelo homem no período paleolítico protegidas das ações do tempo, elas conservaram-se até os dias atuais, onde essas imagens demonstram um pouco do cotidiano dessas pessoas.

Então, é possível notar que mesmo na pré-história, o homem já desenvolvia técnicas para se comunicar e mostrar suas experiências de vida através desse recurso natural tão importante para todos os seres vivos.

\section{RESULTADOS E DISCUSSÃO}

As experiências práticas foram desenvolvidas com 13 alunos de uma turma do $8^{\circ}$ ano do ensino fundamental II, da Escola Municipal Judith Barbosa de Paula Rêgo, localizada no município de Queimadas -PB, através do Programa Residência Pedagógica.

Num primeiro momento para que houvesse a realização das práticas, foi passado o conteúdo (teoria) para os alunos a respeito da temática sobre o solo, destacando a importância da cobertura vegetal, para evitar a erosão laminar e linear. Em seguida aplicaram-se dois questionários com perguntas a respeito do que eles tinham entendido sobre o assunto antes da realização dos dois experimentos, e se sabiam os prováveis resultados que seriam obtidos através das práticas. Após a aplicação dos questionários, foram realizados os 
experimentos, no qual durante a realização houve a discussão do que se tinha aprendido na parte teórica, dessa forma, unindo a teoria com a prática.

Destaca-se que as práticas de solos foram obtidas na experimentoteca de solos da Universidade Federal do Paraná (UFPR). O primeiro experimento tratou-se da importância da cobertura do solo e redução da erosão. Sendo assim, nesse experimento observou-se a erosão laminar que remove uma delgada e uniforme camada do solo superficial, provocada por fluxo hídrico não concentrado e a erosão linear que é decorrente da ação do escoamento hídrico superficial concentrado, apresentando três tipos, os sulcos, ravinas e voçorocas.

Para sua realização foram utilizadas 3 garrafas (PET) de 2 litros, aproximadamente $3 \mathrm{Kg}$ de solo destorroado, touceira de grama do tamanho da garrafa pet de 2 litros, gravetos de árvores para representar a cobertura vegetal morta, tesoura, 3 caixas de sapatos para criar uma inclinação, para que a água escorresse através da boca da garrafa, 3 pratos descartáveis (estilo cumbuca), para colocar abaixo da boca de cada garrafa e 1 recipiente para armazenar a água a ser utilizada para derramar sobre as garrafas. Nas Figuras 2 e 3, é possível observar a montagem e o resultado obtido na realização do experimento, respectivamente.

Figura 2: Montagem do experimento de solo sobre a importância da cobertura vegetal

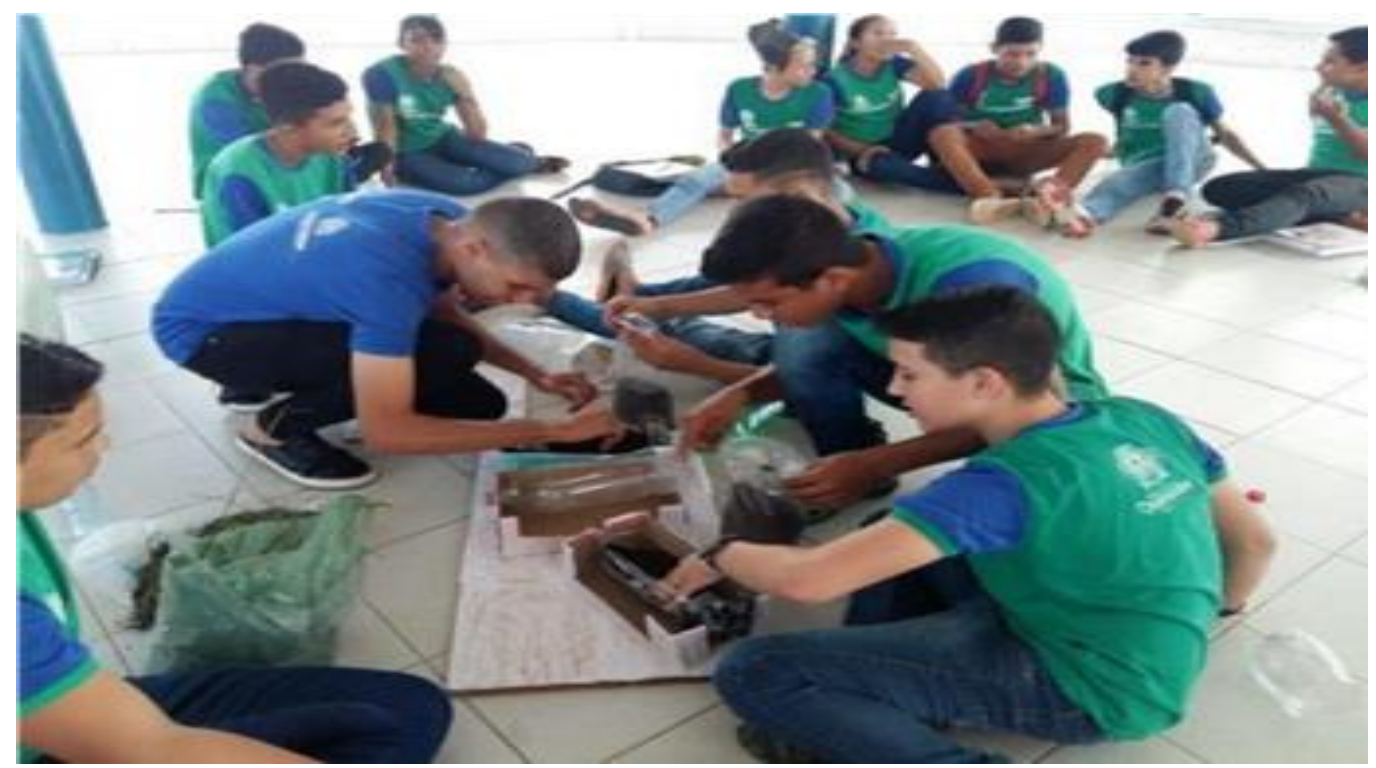

Fonte: Santos, 2019. 
Figura 3: Resultado obtido do experimento sobre a importância da cobertura vegetal, deve-se observar a coloração da água e se há ou não perda visual de solo

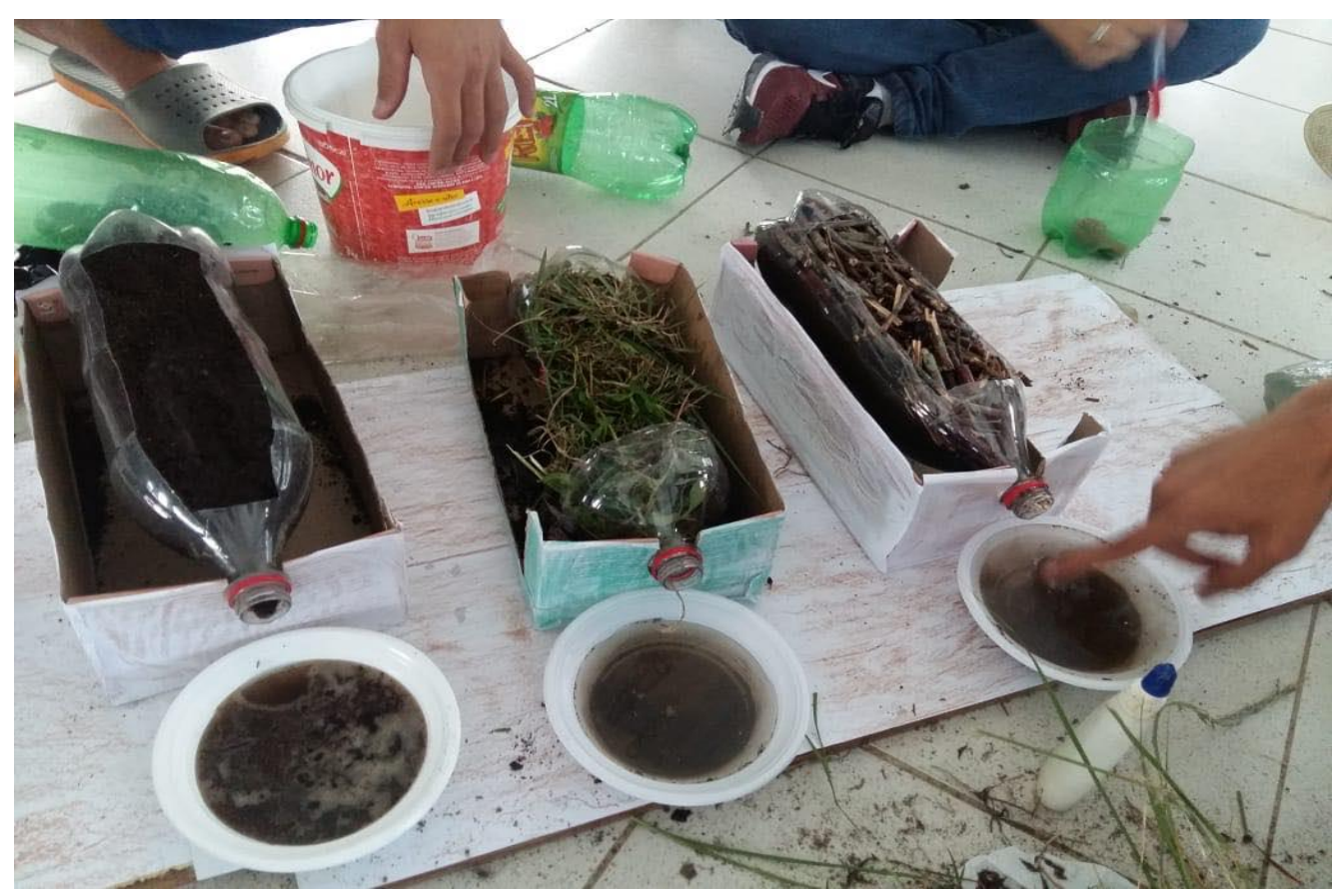

Fonte: Santos, 2019.

Antes da realização do primeiro experimento sobre a importância da cobertura vegetal aplicou-se um questionário para os alunos levantarem hipóteses sobre o que iria acontecer ao realizar o experimento. No quadro 1, é possível observar-se as perguntas que foram aplicadas aos alunos.

Quadro 1: Questionário aplicado com os alunos antes da realização do primeiro experimento

\begin{tabular}{|l|}
\hline \multicolumn{1}{|c|}{ QUESTÕES } \\
\hline 1. Qual a diferença entre a cobertura do solo nas garrafas de $2 \mathrm{~L}$ \\
apresentadas?
\end{tabular}

Fonte: Adaptado da Experimentoteca de solo da UFPR (2019)

Com relação a cobertura de solo apresentada nas 3 garrafas de 2 litros, os 13 alunos relataram que uma das garrafas não apresentava nenhuma cobertura 
sobre o solo, a segunda apresentava uma cobertura vegetal viva e a terceira e última garrafa uma cobertura vegetal morta (observar a figura 3). Apesar de todos os alunos saberem diferenciar as coberturas dos solos contidas nas garrafas, apenas 3 dos 13 alunos conseguiram responderem com mais clareza o que iria acontecer quando derramasse água em cada uma das garrafas. Os 3 estudantes que conseguiram responder de forma mais coerente, afirmaram que na garrafa sem nenhuma cobertura vegetal, iria perder-se uma maior quantidade de solo e as outras duas uma menor quantidade, porém, eles não destacaram questões como ficaria o aspecto da água e para onde iria os sedimentos que seriam levado daquele determinado solo.

Desse modo depois da realização do experimento sobre a cobertura vegetal apresentado através das Figuras 2 e 3, os alunos responderam mais um questionário para que houvesse a discussão dos resultados obtidos e para que se pudesse analisar-se melhor o que os estudantes compreenderam sobre os assuntos retratados no experimento. No quadro 2, é possível observar o questionário aplicado aos estudantes.

Quadro 2: Questionário aplicado com os alunos depois da realização do primeiro experimento

\begin{tabular}{|c|}
\hline QUESTÕES \\
\hline 1. O que foi possível visualizar em cada garrafa? \\
\hline 2. Em qual garrafa houve uma maior perda de solo? E menor? \\
\hline 3. Qual a importância de preservar a cobertura vegetal do solo? \\
\hline
\end{tabular}

Fonte: Adaptado Experimentoteca de solos UFPR (2019)

Os alunos após a realização do experimento, conseguiram observarem e analisarem alguns aspectos da água oriunda do escoamento superficial em cada uma das garrafas. Na primeira garrafa (da esquerda para a direita), os estudantes analisaram que o solo sem nenhuma cobertura vegetal, a água oriunda do escoamento superficial do solo estava mais turva (suja) do que as provindas do solo com cobertura vegetal viva e morta. Desse modo, constatouse que o solo sem nenhuma cobertura vegetal fica totalmente desprotegido da 
ação da chuva, causando a perda dos seus nutrientes e sedimentos que são carregados pelas águas e depositados nos lugares mais baixos. Assim, na primeira garrafa, sem cobertura vegetal, observou-se o efeito nítido da erosão linear.

Com relação a segunda e terceira garrafa (da esquerda para a direita), respectivamente, os alunos analisaram que houve uma menor perda de solo, pois a vegetação viva e morta, protegem o solo do efeito da chuva, diminuindo os efeitos da erosão. Porém, observou-se que o escoamento superficial formou pequenos canais levemente definidos, tendo o desgaste uniforme e gradual do solo em toda a sua extensão, caracterizando a erosão laminar. Destaca-se que a menor turbidez da água do escoamento indica uma menor perca de partículas minerais e orgânicas do solo.

No segundo experimento realizado, teve como base o impacto da gota de chuva no solo, que mostrava-se também a importância da cobertura vegetal para o solo, pois um solo sem cobertura vegetal, com o impacto das gotas da chuva, ocasiona a sua desagregação. Nesse sentido, os objetivos do experimento foi demonstrar o início da erosão hídrica do solo causada pelo impacto da gota de chuva; discutir os fatores que causam a erosão hídrica do solo, destacando os seus efeitos e os problemas ambientais causados por esse tipo de erosão.

Antes da realização do experimento aplicou-se um questionário com 3 perguntas que poderão ser vista no quadro 1 para que os alunos formulassem hipóteses do que iria acontecer. Dos 13 alunos que participaram dos experimentos, todos responderam que a principal diferença era que uma garrafa estava coberta de grama e outra só tinha solo, sem nenhuma cobertura vegetal. Quando perguntados com relação ao que iria acontecer quando simulasse a chuva, apenas 4 alunos dos 13 afirmaram que na garrafa com o solo descoberto, sem cobertura vegetal, o papel iria "melar" de solo e na garrafa com cobertura vegetal, não iria "melar" o papel, pois a grama estava cobrindo o solo.

Destaca-se que apenas os 4 alunos que deram sua sugestão do que iria acontecer quando houvesse a simulação da chuva, foram os mesmos que deram uma resposta sobre os resultados que seriam obtidos, relatando que iria acontecer o "salto" de solos, quando jogasse a água na garrafa sem cobertura 
vegetal, melando o papel e nada iria acontecer com o papel que estava envolvido na garrafa com cobertura vegetal.

Quadro 3: Questionário aplicado com os alunos antes da realização do segundo experimento

\begin{tabular}{|ll|}
\hline \multicolumn{1}{|c|}{ QUESTÕES } \\
\hline 1. & Existe alguma diferença na cobertura do solo nas duas garrafas? Qual? \\
\hline 2. O que você acha que irá acontecer quando derramar a água nas garrafas \\
sem cobertura vegetal e com cobertura vegetal?
\end{tabular}

Fonte: Adaptado da Experimentoteca de solos da UFPR (2019)

Para a realização do experimento utilizou-se 2 garrafas (PET) de 2 litros, 1 garrafa (PET) de 1 litro, aproximadamente $2 \mathrm{~kg}$ de solos, um tufo de grama de jardim com solo aproximadamente do mesmo diâmetro da garrafa PET, 2 folhas de papel sulfite de cor branca e fita adesiva transparente. Para cortar o tufo de grama pode-se utilizar uma faca firme ou uma pá de jardinagem. As Figuras $4 \mathrm{e}$ 5 apresentam os materiais e o modo de realização dessa estratégia.

Figura 4: Experimento sobre o impacto das gotas de chuva no solo

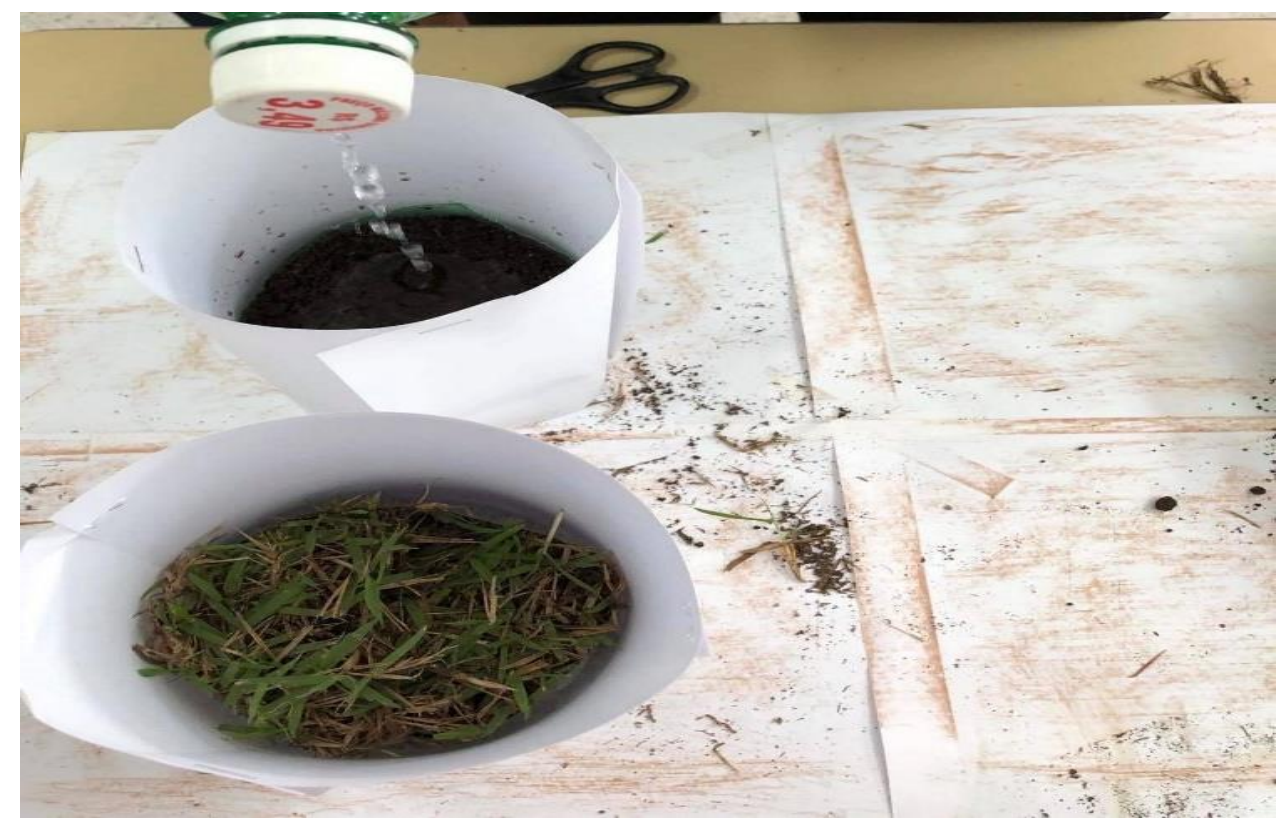

Fonte: Santos, 2019. 
Figura 5: Resultado obtido do experimento sobre o impacto das gotas de chuva no solo, deve-se observar a quantidade de solo desagregado, evidenciado no papel sulfite

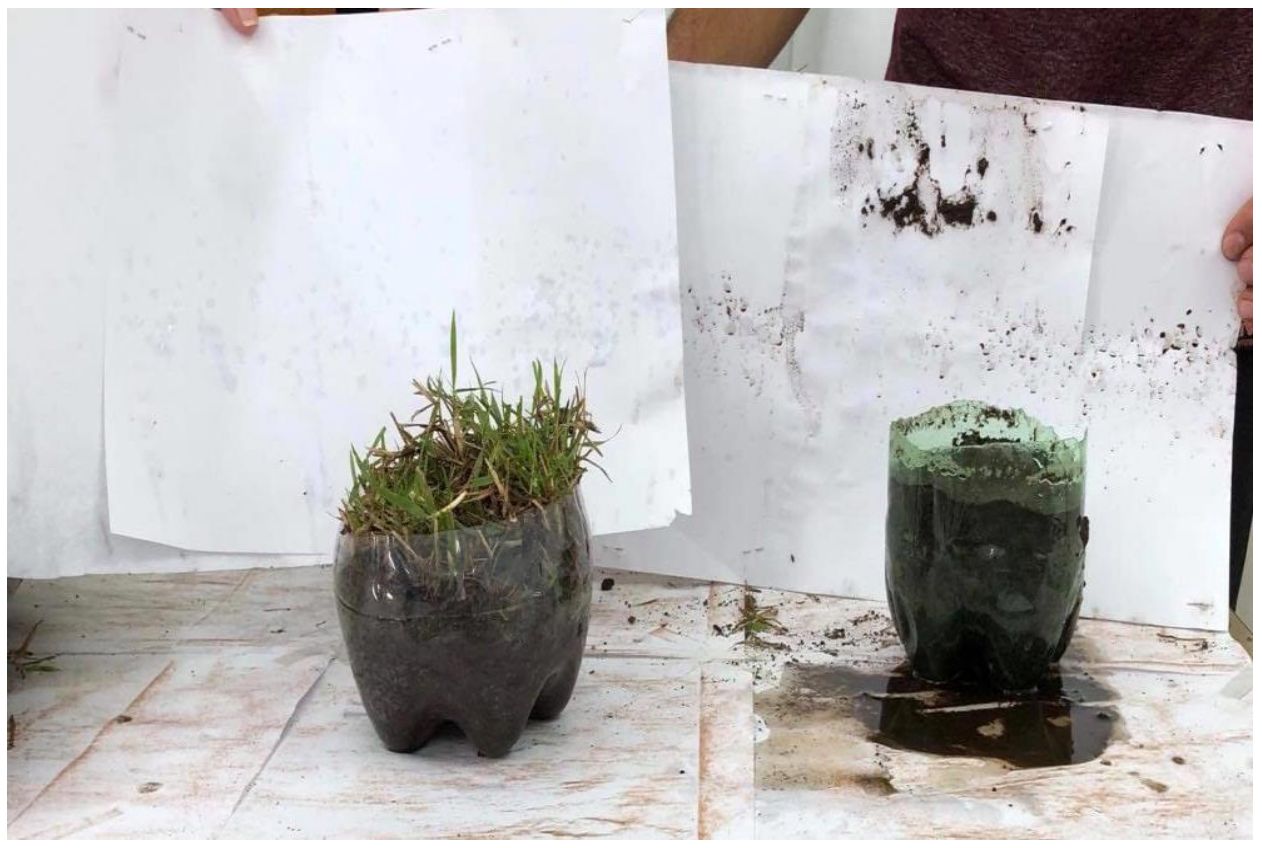

Fonte: Santos, 2019.

Após a realização dos experimentos mostrados nas Figuras 4 e 5, os alunos responderam outro questionário, transcrito no Quadro 4.

Quadro 4: Questionário aplicado com os alunos depois da realização do segundo experimento

\begin{tabular}{|l|}
\hline \multicolumn{1}{|c|}{ QUESTÕES } \\
\hline 1. O que foi possível observar nos papeis sulfites? \\
\hline 2. Em qual garrafa houve mais perda de solo? \\
\hline 3. É importante preservar a cobertura vegetal do solo? Por quê? \\
\hline 4. Para onde vai o solo perdido pela erosão \\
\hline 5. A partir do experimento foi possível compreender melhor o \\
conteúdo? Por quê?
\end{tabular}

Fonte: Adaptado da Experimentoteca de Solos da UFPR (2019)

A partir das respostas apresentadas pelos alunos observou-se que todos relataram que o papel sulfite que estava envolvido sobre a garrafa PET com cobertura vegetal estava apenas molhado, não havendo desagregação do solo, já 
com relação ao papel sulfite da garrafa PET sem cobertura vegetal, estava todo "melado" de solo, pois houve a desagregação do solo. Desse modo, os discentes constataram que na garrafa sem cobertura vegetal houve uma perda de solo. Assim, notou-se que a vegetação é a defesa natural do solo ao processo erosivo, pois ela intercepta a água, fazendo diminuir a quantidade que chega ao solo, contribuindo para um menor escoamento superficial, pois o solo irá reter uma maior quantidade de água.

Todos os estudantes relataram também que a cobertura vegetal além de proteger o solo, serve de alimento para os animais que se alimentam das folhas, sementes e frutos, e quando o ser humano retira a vegetação através do desmatamento e das queimadas, os animais ficam sem a alimentação, pois aqueles determinados animais só estão naquela determinada área pois possuem o alimento, quando não possuem o que comerem, precisam migrarem para outros locais, alguns até morrendo, pois são queimados durante as queimadas e outros porquê não conseguem se adaptarem a outros ambientes.

Quando perguntados sobre para onde vai o solo perdido pela erosão os alunos responderam para os fundos de rios, lagos e lagoas, preenchendo-os de sedimentos causando o assoreamento. $O$ interessante é que já havia-se sido discutido o conteúdo com os alunos antes da prática, e eles citaram como exemplo de um açude que está perdendo a sua capacidade, pois está sendo preenchido por sedimentos, o açude Epitácio Pessoa, mais conhecido como o "Açude de Boqueirão", situado na cidade de Boqueirão no Estado da Paraíba, responsável por abastecer a cidade de Queimadas, onde situa-se a escola na qual os alunos estudavam.

Nesse sentido, ao analisar o desempenho dos alunos ao realizarem os experimentos de solo na escola e as respostas apresentadas nos questionários após a realização dos experimentos, observou-se que os alunos entenderam a importância da preservação da cobertura vegetal para o solo e para a manutenção da vida, pois a cobertura vegetal mantém a umidade do solo, fazendo com que as partículas se agreguem mais facilmente, fazendo com que haja o aumento de matéria orgânica e nutrientes no solo e ainda serve como alimento para os diversos animais e os próprios seres humanos. 
Destaca-se também que antes da realização dos experimentos, os alunos em sua maioria não sabiam responderem o que iria acontecer com o solo sem cobertura vegetal e com cobertura vegetal. Assim, eles sabiam a teoria, mas não sabiam o que acontecia na prática. Então a partir das simulações geradas com a utilização dos experimentos de solo, os estudantes puderam ver as

consequências causadas pela ação humana sobre o solo, despertando a curiosidade dos mesmo, que demonstraram a todo momento o interesse em participar das discussões a partir da realização das práticas realizadas sobre a erosão do solo. Portanto com a realização das práticas os discentes conseguiram estabelecer uma relação entre a teoria e a prática, compreendendo os conteúdos trabalhados de uma forma dinâmica e divertida.

Decerto, avalia-se que cabe ao professor buscar sempre utilizar novas metodologias para se trabalhar os conteúdos, tornando as aulas dinâmicas e contextualizadas. Dessa forma, despertando nos alunos o interesse pelos estudos, pois atualmente o que se observa é o desinteresse por parte da maioria dos alunos, que se sentem desmotivados em continuarem os estudos.

\section{CONSIDERAÇÕES FINAIS}

O Programa Residência Pedagógica exerce um papel fundamental na formação do professor para a sala de aula, pois tudo que é aprendido na teoria é passado para a prática no ensino fundamental e médio, além do fato de que com a residência há uma integração entre as escolas participantes, universidades e secretarias de educação, proporcionando uma melhor qualidade no ensino das escolas participantes.

A realização dos experimentos de solos durante o programa Residência Pedagógica, foram bastante importantes no processo de ensino e aprendizagem dos alunos, pois, observou-se na prática tudo aquilo que tinha sido passado como teoria em sala de aula. Sendo assim, destaca-se a importância do uso de experimentos de solos no ensino de Geografia e das outras diversas áreas do conhecimento, como forma de trazer o conteúdo para próximo da realidade do aluno, fazendo-o conhecer a respeito da importância de se preservar o solo para manter a biodiversidade e os próprios seres humanos. 
Através dos resultados obtidos comprova-se que a utilização de recursos diferentes em sala de aula melhora o aprendizado dos alunos, que mostram em sua maioria um maior interesse pelo assunto, pelo fato que estão realizando as práticas, e obtendo os resultados naquele mesmo momento, o que estava só na sua imaginação, se torna realidade.

Desse modo, a partir do momento que os professores desenvolvem metodologias que fujam do tradicional, da novas ressignificações ao ensino de Geografia, pois trabalham-se os conteúdos a partir de situações que ocorrem ou podem ocorrer no cotidiano dos alunos, um exemplo, é através de recursos didático-pedagógicos que estimulam os estudantes a participarem das aulas, não as tornando monótonas, desenvolvendo também neste caso, o papel social de conscientizá-los sobre a importância da conservação dos solos.

Assim, faz-se necessário repensar na prática pedagógica no sentido de problematizar o ensino de solo, alinhado a uma proposta investigativa que contribua para que o aluno valorize esse saber afim de estabelecer as relações necessárias com o contexto em que está inserido. Dessa forma, as práticas de solos proporcionam a construção do conhecimento, e ainda fazem com que o professor se aproxime mais dos alunos, pois todos se envolvem na realização dos experimentos. Logo, é necessário que o professor esteja apto para realizar os experimentos, como um recurso didático, objetivando que o aluno possa aprender o conteúdo da melhor forma possível.

\section{REFERÊNCIAS}

ALTHAUS, M. T. M. Didática: da análise de suas contribuições nos cursos de Licenciatura da Universidade Estadual de Ponta Grossa à análise de suas repercussões na prática pedagógica do professor da escola pública. Dissertação (Mestrado). UEPG. 1997. 140 p.

ARAUJO, Gustavo Henrique de Souza; ALMEIDA, Josimar Ribeiro de; GUERRA, Antonio José Teixeira. Gestão Ambiental de áreas

degradadas. 5. ed. Rio de Janeiro: Bertrand Brasil, 2010.

BOARDMAN, J. IN: GUERRA, A.J.T., SILVA, A.S. \& BOTELHO, R.G.M. (org). Erosão e conservação dos solos: conceitos, temas e aplicações. Rio de Janeiro: Bertrand Brasil. ${ }^{\mathrm{a}}$ ed. 340p. 1999. 
CASTOLDI, R.; POLINARSKI, C. A. A utilização de Recursos DidáticoPedagógicos na Motivação da Aprendizagem. In: SIMPÓSIO NACIONAL DE ENSINO DE CIÊNCIA E TECNOLOGIA, I, 2009, Ponta Grossa - PR. Anais do I Simpósio Nacional de Ensino de Ciência e Tecnologia - SINECT, Ponta Grossa - PR: UTFPR, 2009, p. 684 692. Disponível em: https: \\atividadeparae ducacaoespecial.com $\backslash$ wp-content $\backslash$ uploads $\backslash 2014 \backslash 09 \backslash$ recursosdidaticopedag\%C3 \%B3gicos.pdf. Acesso em: 20 de nov. 2018.

FRASSON, V.R.; WERLANG, M.K. Ensino de solos na perspectiva da educação ambiental: contribuições da ciência geográfica. Geografia: educação e pesquisa, Santa Maria, v. 14, n.1, 2010.

FREIRE, P. Pedagogia da autonomia - Saberes necessários à prática educativa. São Paulo: Paz e Terra, 1996 (Coleção Leitura).

GOMBRICH, E.H. História da arte. $6^{\text {a }}$ edição. ARCA LTCO, 2008 HISTÓRIA da Arte Medieval. Disponível em: <http: \|www.girafamania.com.br \historia_a rte $\backslash$ historia_artemedieval.html $>$. Acesso em 23 de outubro de 2013.

IMBERNÓN, F. Formação continuada de professores. Porto Alegre: Artmed, 2010.

LIMA, Maria Socorro Lucena; GOMES, Marineide de Oliveira. Redimensionando o papel dos profissionais da educação: algumas considerações, In: PIMENTA, Selma Garrido; GHEDIN, Evandro. Professor reflexivo no Brasil: gênese e crítica de um conceito. (Orgs.) -2 Ed. São Paulo: Cortez, 2002.

LIMA, V.C.; LIMA, M.R.; SIRTOLI, A.E.; SOUZA, L.C.P.; MELO, V.F. Projeto Solo na Escola: o solo como elemento integrador do ambiente no ensino fundamental e médio. Expressa Extensão, Pelotas, v. 7, n. especial, 2002.

LIMA, V. C.; MELO, V. F. Perfil do solo e seus horizontes. In: O solo no meio ambiente: abordagem para professores do ensino fundamental e médio e alunos do ensino médio. Curitiba: Departamento de Solos e Engenharia Agrícola, p.11-16, 2007.

LUDKE, M.; ANDRÉ, M. E. D. A. Pesquisa em educação: abordagens qualitativas. São Paulo: EPU, 1986.

MOREIRA, I. V. D. Vocabulário Básico do Meio Ambiente. Rio de Janeiro: Feema \Petrobrás, 1992.

MUGGLER, C.C., SOBRINHO, F.A.P. \& MACHADO, V.A. Educação em solos: princípios, teoria e métodos. Revista Brasileira de Ciência do Solo, 30:733-740, 2006.

NUNES, M. S.; AZEVEDO, R. J. G.; SILVA, P. E. A. B. A abordagem de conteúdos relativos à ciência dos solos em livros didáticos de geografia para $\mathrm{o}$ ensino médio. Revista de Geografia - PPGEO - UFJF, v. 6, n. 3, p.271-281, 
2016. Disponível em: https: $\backslash \mid w w w . ~ u f j f . b r ~ \$ index.php $\backslash$ geografia $\backslash$ article $\backslash$ view $\backslash 18$ o31. Acesso em: 12 dez. 2018.

RUELLAN, A. Pedologia e desenvolvimento: a ciência do solo a serviço do desenvolvimento. In: MONIZ, A. C.; FURLANI, A. M. C.; FURLANI, P. R.; FREITAS, S. S. (eds.) A responsabilidade social da ciência do solo. Campinas: Sociedade Brasileira de Ciência do Solo, 1988.

SOUZA, S. E. O uso de recursos didáticos no ensino escolar. In: I Encontro de Pesquisa em Educação, IV Jornada de Prática de Ensino, XIII Semana de Pedagogia da UEM: "Infância e Práticas Educativas". Arq Mudi. 2007. Disponível em: http://www.pec_uem \revistas \arqmundi\volume_11 \|supleme nto_02 $\backslash$ artigos $\backslash 019 . d f$. Acesso em: 12 de jan. 2013

Recebido em 24 de março de 2020

Aceito em 22 de junho de 2020 